$\begin{array}{lll}\begin{array}{l}\text { Trade secret } \\ \text { Kenyan discovery has } \\ \text { led to a potential } \\ \text { HIV vaccine } \\ p 6\end{array} & \begin{array}{l}\text { Join up } \\ \text { Report says fusion } \\ \text { scientists are too } \\ \text { isolated } \\ p 7\end{array}\end{array}$

\title{
Inquiry blames missed warnings for scale of Britain's BSE crisis
}

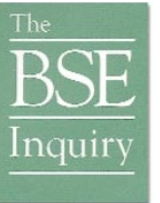

Peter Aldhous, London

"Beef is safe." That supposedly comforting phrase became a mantra for the British government after bovine spongiform encephalopathy (BSE) emerged in the late 1980s. No wonder the public felt betrayed when on 20 March 1996 they were told by the same government that a handful of deaths from a new variant of Creutzfeldt-Jakob disease (vCJD), an invariably fatal neurodegenerative condition, were probably linked to BSE.

The long-awaited report from the public inquiry into the official handling of Britain's BSE epidemic, released last week, concludes that ministers and civil servants did not deliberately lie to the public - they genuinely believed that the risks were minimal.

But it identifies institutional deficiencies which led to a mistaken campaign of reassurance that failed to reflect the shifting state of scientific knowledge. "Most of those responsible for responding to the challenge posed by BSE emerge with credit," says the report, from a team headed by the judge Lord Phillips. "However, there were a number of shortcomings in the way things were done."

The report's lessons should reverberate internationally. And it has already been delivered to the governments of other Euro-
Phillips: says that British ministers believed the risks to the public were minimal.

pean Union states - some of which are now wrestling with their own emerging BSE outbreaks, linked to imported British cattle feed.

The inquiry's report documents failings in the scientific advisory system that delayed measures that might have reduced the size of Britain's BSE epidemic, or limited the amount of potentially infective material entering the human food chain. It addresses deficiencies in the organization of BSE research (see page 5). And it illustrates how the conclusion that BSE was likely to pose only a "remote" risk to human health, reached by a scientific advisory panel in February 1989, was allowed to dominate official thinking right up until the fateful 1996 announcement - even in the face of growing scientific evidence that should have raised warning signs to the contrary.

BSE, CJD and scrapie, a related disease of sheep, are mysterious conditions that are now widely thought to be caused by prions. These are misshapen variants of a protein called $\mathrm{PrP}$. The prions seem to cause normal versions of the protein to adopt their own, distorted configuration. This results in the formation of insoluble clumps of protein in the brain, which seem to kill neighbouring cells.

When BSE emerged, the prion theory

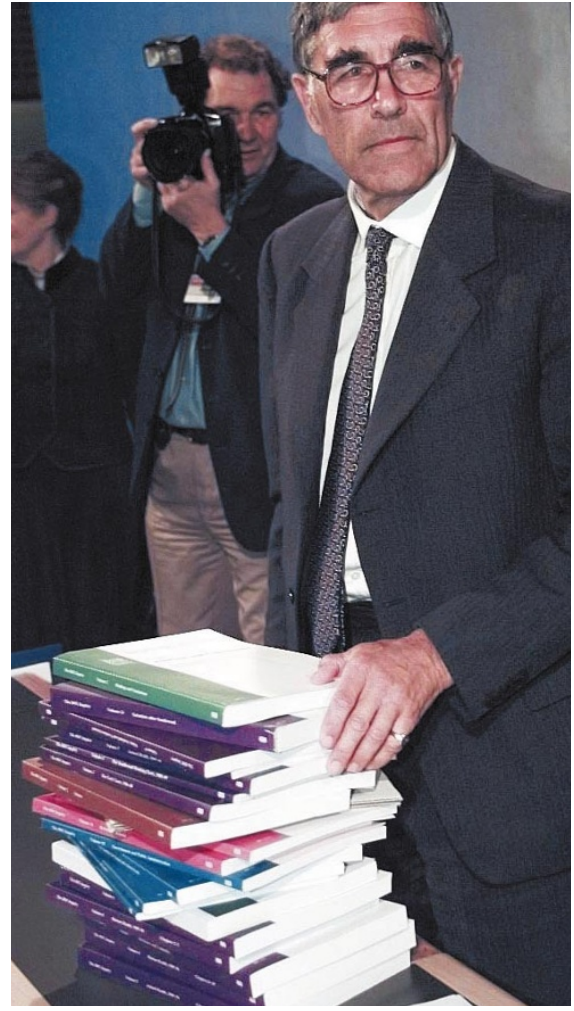

had yet to win widespread acceptance. But the first scientific committee to consider the issue, headed by Richard Southwood, a

\section{Were some CJD victims infected by vaccines?}

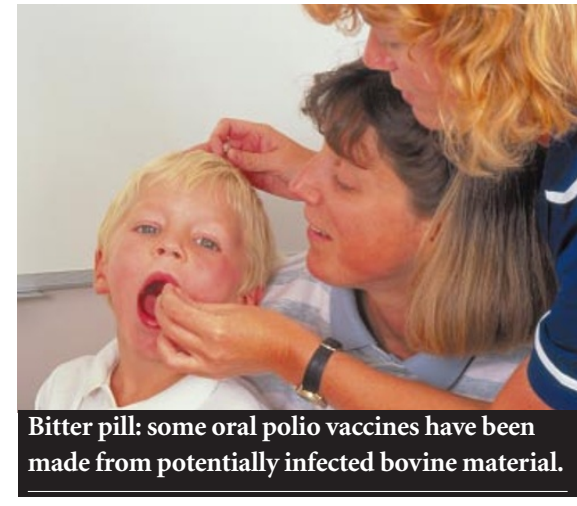

NATURE | VOL $408 \mid 2$ NOVEMBER $2000 \mid$ www.nature.com

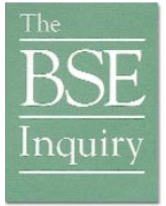

Karen Birmingham, London Although food has been the overwhelming object of attention as the source of infection with variant Creutzfeldt-Jakob disease (vCJD), there is a possibility that some of the victims - who are predominantly young adults - might have contracted the disease through immunization.

The BSE inquiry's report (see above) calls for vaccines to be investigated as a possible route of transmission. But it concedes that this will be hampered by the

\footnotetext{
$\approx \odot 2000$ Macmillan Magazines Ltd
}

fact that "systematic records of the action taken in response to BSE in respect of individual medical products are lacking".

Indeed, the report reveals that the pharmaceuticals industry and related government agencies failed to grasp the extent of the risk, and delayed removing potentially harmful products from the public arena. It notes that this behaviour persisted longer than corresponding problems in the meat industry, without attracting similar parliamentary and public scrutiny.

Some vaccines are made using culture media derived from cattle tissue. Although 
zoologist at the University of Oxford, drew comfort from the parallels with scrapie. This disease had shown no evidence of posing a risk to human health.

Southwood's working party was told by John Wilesmith, then the sole qualified veterinary epidemiologist within the Ministry of Agriculture, Fisheries and Food (MAFF), that scrapie-infected sheep were the most likely source of BSE infection. Wilesmith correctly identified meat and bone-meal in cattle feed as the prime culprits. He noted that the first recorded cases of BSE appeared several years after the processes for rendering animal carcasses into feed were changed. He concluded that this had allowed the scrapie agent to remain active and infect cattle.

\section{Early advice}

At their first meeting in June 1988, Southwood and his colleagues were shocked to learn that cattle known to have BSE were still entering the human food chain. They advised that this should be stopped. According to Phillips, the government should have taken this action earlier. "Reference to outside committees involves delay," says his report. "It should be avoided, where possible, in situations of urgency." Indeed, the report says that, in general, the government relied too heavily on outside experts, and should build up its in house scientific expertise.

In addition to Southwood, the working party comprised three other eminent scientists: a virologist, a neurologist and a veterinarian. This typified the practice - then common in Britain, but not uniquely British - of taking advice from a small committee of scientists known personally to government officials, and not necessarily experts in the narrow field under scrutiny. In future, the Phillips report concludes, committees "should include experts in the areas of advice that is likely to be required".

The Phillips report also identifies specific deficiencies in the advice delivered by Southwood in February 1989 — the working party

guidelines asking drugs companies to get this material from countries with BSE-free herds were issued in 1989 by the Committee on Safety of Medicines (CSM), they will not become law until March 2001. Companies have been relied on to follow the guidelines voluntarily. Yet only last month, it emerged that one company, Medeva, had continued to use bovine serum from British herds to make an oral polio vaccine (see Nature 407, 936; 2000). The Department of Health delayed release of this news for two months.

Alarmingly, vaccines produced after the point at which the BSE epidemic had been identified - possibly using British bovine material - were still in use as recently as November 1993. According to the inquiry's

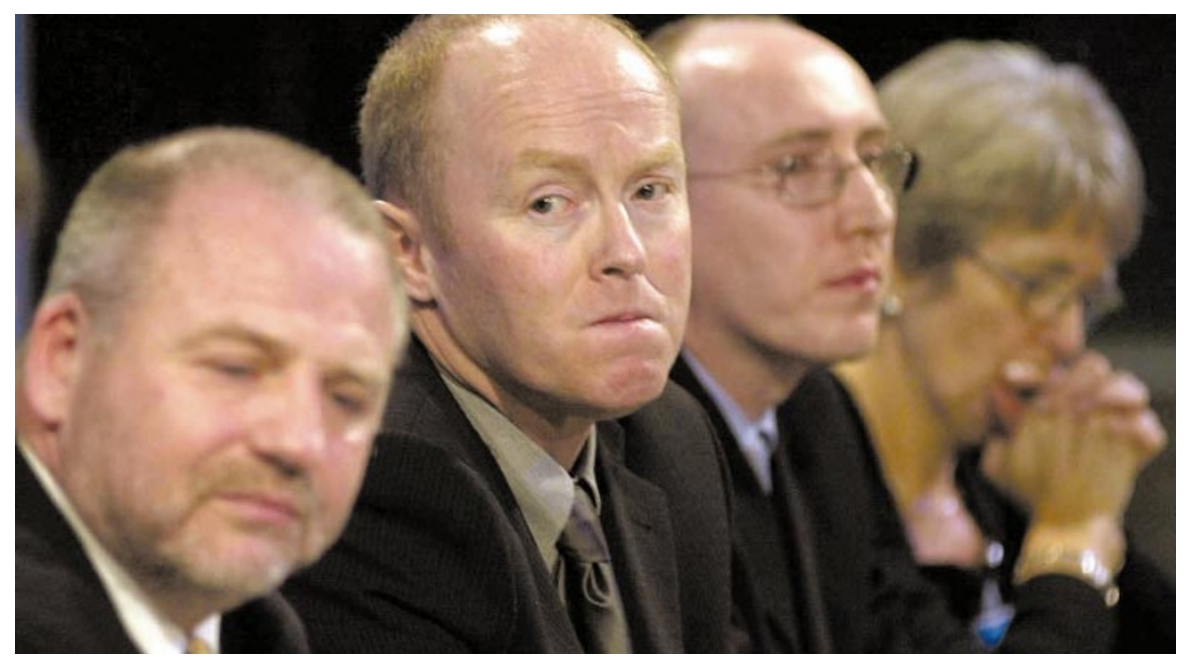

The wait is over: relatives of those infected by vCJD attended the release of the BSE inquiry's report.

is among those explicitly criticized. Although the group acknowledged that, if its assumptions were incorrect, the implications would be extremely serious, Phillips faults the working party for not making clear that it had not seen the data on which Wilesmith's epidemiological conclusions were based.

Those data were restricted by MAFF to Wilesmith's team until after the vCJD crisis broke in 1996. Only then was an independent team, led by Roy Anderson of the Wellcome Trust Centre for the Epidemiology of Infectious Disease in Oxford, allowed access. Anderson's initial studies (see Nature 382, 779-788; 1996) and subsequent work have cast doubt on some of Wilesmith's conclusions. Anderson now says that cows were probably infected before the changes in rendering practice were introduced, which makes the original scrapie theory less convincing.

\section{Dangerous assumptions}

Whatever the origin of BSE, it soon became clear that the infectious agent at loose in British cattle was different from known strains of scrapie. So, even if it had originally passed from sheep, BSE could no longer be assumed to be equally benign. In 1990, a scare erupted when domestic cats started to go down with a BSE-like disease. The significance was played down by MAFF officials, but scientists were worried because it had never been possible to transmit scrapie to cats. By 1992, a team led by Moira Bruce at the Institute of Animal Health's Neuropathogenesis Unit in Edinburgh had found that BSE was distinct from known isolates of scrapie. And by 1994, she had proved that the cats were infected with BSE.

This evidence was reviewed by the Spongiform Encephalopathy Advisory Committee (SEAC), which advised the government on the BSE epidemic from April 1990. Acknowledging that BSE was not the same as conventional scrapie, SEAC still judged the risk to human health to be remote because tissues known to be potentially infective - the central nervous system and various other bits of offal - were supposed to be removed from the human food chain.

The trouble, according to Phillips, was that officials and ministers were still falling back on Southwood's conclusion of a remote risk to human health. "Right up to 1996 the report, the chief medical officer of the day, Donald Acheson, decided to phase out the existing stocks because new batches of vaccines take time to grow, and medical experts considered that the benefit of maintaining a continuous national immunization programme outweighed the risk of interrupting it.

These decisions were taken in the absence of knowledge about how infective bovine materials used to make vaccines might be. It was only in 1993 that the Neuropathogenesis Unit in Edinburgh obtained test results that showed bovine serum did not cause infection in mice - studies that the inquiry's report describes as "inconclusive".

But in some sections, the report is sympathetic to the difficulties of withdrawing medicines from use quickly. Product licences would have had to have been revoked on an individual basis, so each licence holder could have appeared before the relevant committee to argue against withdrawal. "This would have been a logistical nightmare," says the report. "It is not surprising that the decision was taken to issue guidelines rather than attempt to use formal statutory powers."

Last week it was also revealed that the Department of Health asked the CSM as recently as March this year to produce a comprehensive assessment of BSE-related issues in vaccines. There has been no indication when this evaluation will be made public. 
Southwood Report was cited as if it demonstrated as a matter of scientific certainty, rather than provisional opinion," the report notes. As a result, precautionary measures designed to protect both people and cattle from infection were not rigorously enforced.

Phillips also identifies specific breakdowns in communication that exacerbated the situation. For instance, many SEAC members remained unaware that mechanical recovery techniques, used to strip meat from the spinal column, were likely to allow traces of spinal cord to get into meat products. As a result, SEAC did not suggest that the practice should be banned until November 1995. And one key piece of evidence that first emerged in November 1990, showing that BSE had been passed to a breed of sheep resistant to scrapie, was never commented on by SEAC.

\section{Protecting the future}

Several principles to stop such failings are outlined by the Phillips report. It says that scientific advice should state the reasons for its conclusions, and that underlying assumptions should be made clear. Where appropriate, the advice should set out the different policy options and the implications of each.

The report also advocates greater openness, and stresses that officials and minister must recognize when the expertise of scientists ends, and decisions have moved into the

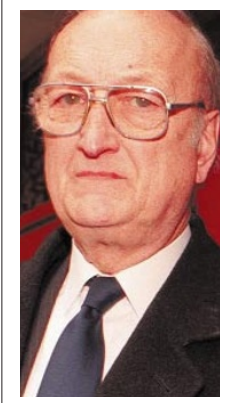
policy arena. "Scientist were expected to provide all the answers, where sometimes this was not their proper role," says Phillips.

The recommendations will not surprise British scientists, as almost all of them have already been introduced by Robert May, the government's chief sciSouthwood: his panel comes under fire. entific adviser until two

What will surprise some scientists are the statements about BSE's origins made in the Phillips report. It says that the disease "probably originated from a novel source in the early 1970s, possibly a cow or other animal that developed disease as a consequence of gene mutation". Some feel that this goes beyond the available evidence. "It is likely to be impossible to know," says Anderson, who will soon take up a post at Imperial College, London.

The current government seems to feel this point needs clarification, and has said it intends to commission an independent review of scientific understanding of the origins of the BSE epidemic. Researchers in the field hope that this does not deflect attention from the most urgent priorities, which include developing a test to identify animals and people incubating the disease, and drugs to treat vCJD victims.

http://wwww.bseinquiry.gov.uk

\section{Scientific turf war 'delayed potentially vital research'}

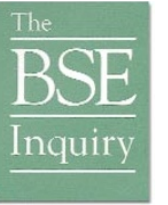

David Dickson, London

Individual scientists may have largely escaped criticism in Britain's BSE inquiry, chaired by Lord Phillips. But the inquiry's report sharply highlights critical weaknesses in the way research decisions were made.

In particular, the report suggests that turf fights between the research councils and government departments may have delayed vital research in the early 1990s. Such tensions, it reveals, undermined efforts in 1990 by Donald Acheson, then chief medical officer at the Department of Health, to give responsibility for BSE-related research to a single research supremo. Scientists looking at the implications of the BSE crisis are likely to focus on the factors that led to this failure.

Acheson wanted a single individual to be responsible for identifying key research needs and commissioning the appropriate additional research in a way that had already been successfully applied to the AIDS epidemic. The Phillips report identifies various areas - such as experimental testing of the 'scrapie' hypothesis (see main story) and the development of a reliable diagnostic blood test - where progress might have been more rapid if a supremo had been in place.

But, as evidence submitted to the inquiry shows, the proposal fell victim to a basic distrust between government officials and scientists working in universities or for the research councils. In particular, officials from the Ministry of Agriculture, Fisheries and Food (MAFF) remained adamant that any attempt to develop and monitor a broad research agenda should be under their control - and be directed by a veterinary expert rather than a scientist with a background in fundamental research.

At the same time, according to evidence presented to the inquiry, representatives of the two research councils directly involved - the Medical Research Council and the Agricultural and Food Research Council were keen to remain independent from anything that felt like government interference.

These differences could not be reconciled. And the minutes of a subsequent meeting of government officials records a general feeling that the supremo idea "should be left on one side to die a natural death".

Apart from one area of research - the possibility of maternal transmission of BSE from cows to their calves - the Phillips report rejects the charge that BSE research suffered from inadequate funding.

But it does draw attention to the lack of collaboration between scientists working in government laboratories and non-government researchers. For example, the report points out that scientists from MAFF's Central Veterinary Laboratory (CVL) in Weybridge, Surrey, held back initially from consulting scientists at the Neuropathogenesis Unit (NPU) in Edinburgh. "If the CVL had consulted them at this stage, the NPU would have confirmed that there were very strong indications that this was indeed a new Transmissible Spongiform Encephalopathy," it says.

The evidence unearthed by the Phillips inquiry has provided a rich source of ammunition for those keen to see a reassessment of the division of responsibilities between government and non-government scientists on topics of public concern.

Peter Cotgreave, for example, director of the lobby group Save British Science, says that the one clear lesson is "recognition of the need for the scientific community to get more closely involved" in deciding on research priorities in areas with important policy implications.

Eric Millstone, of the Science Policy Research Unit at the University of Sussex, agrees - but says that this does not necessarily mean passing responsibility for choosing priorities to bodies such as the research councils. "Phillips talks as if scientific research could and should be conducted in a policy vacuum," says Millstone. "But that is unrealistic. The failure of BSE was not that BSE research was being overseen by a government department, but that it was the wrong department."

The Royal Society has already announced plans to carry out a rapid review of the lessons of the BSE crisis for the interaction between the government and science advisory committees. Reacting with unprecedented speed, it has promised that its conclusions will be completed in December.

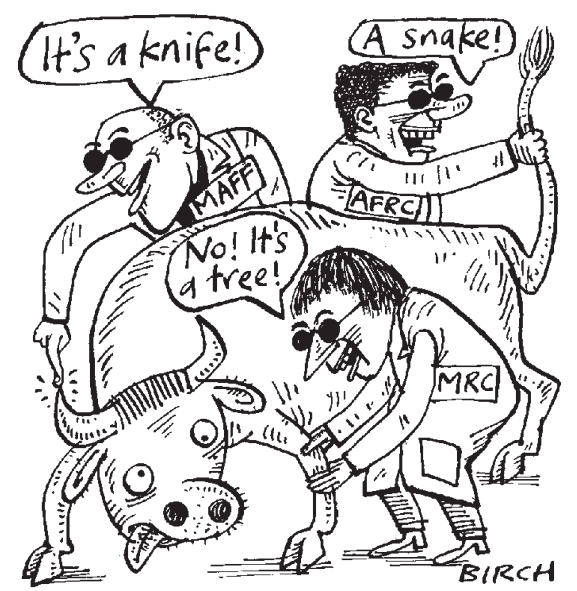

